Electronic Supporting Information

\title{
CdSe Quantum Dot Sensitized Molecular Photon Upconversion Solar Cells
}

Drake Beery, Jonathan P. Wheeler, Ashley Arcidiacono, and Kenneth Hanson*

Department of Chemistry \& Biochemistry, Florida State University, Tallahassee, Florida 32306, United States

*Corresponding author email: hanson@chem.fsu.edu

\section{Contents}

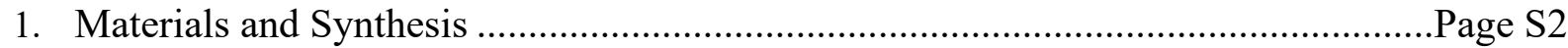

2. Photophysical and Electrochemical Measurements ..............................................Page S3

3. Energy Level Calculations ................................................................................Page S6

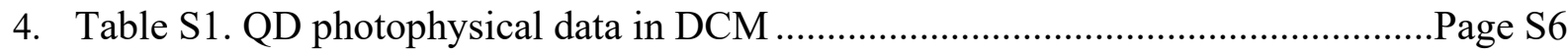

5. Figure S1. 2.7 nm QD absorption and emission spectra ........................................Page S6

6. Equation S1-2. QD size and extinction coefficient calculation ..............................Page S7

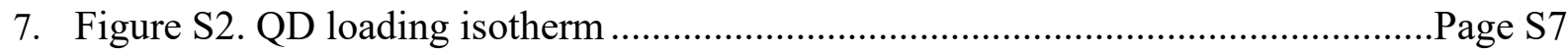

8. Figure S3. Absorption spectra of QD films on $\mathrm{TiO}_{2} \mathrm{w}$ and $\mathrm{w} / \mathrm{o} \mathrm{B}$.........................Page S8

9. Figure S4. Absorption spectra of $\mathrm{TiO}_{2}-\mathrm{B}-\mathrm{QD}$ films after $\mathrm{TiO}_{2}$ treatments ..............Page S8

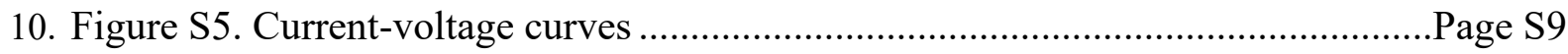

11. Table S2. Device performance metrics ..............................................................Page S9

12. Figure S6. Transient absorption spectra w/ and w/o Co ${ }^{\mathrm{II} / \mathrm{III}}(\text { phen })_{3}$........................Page S10

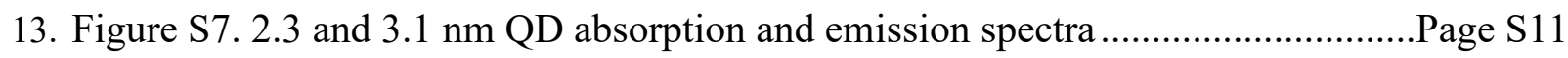

14. Figure S8. Normalized emission spectra for QDs of different diameters .................Page S11

15. Figure S9. Amperometric $i$ - $t$ data for 2.3 and $3.1 \mathrm{~nm}$ diameter QD .......................Page S12

16. Figure S10. Time-resolved emission data for 2.3 and $3.1 \mathrm{~nm}$ diameter QD ............Page S12

17. Table S3. Kinetic fit parameters for time-resolved emission data..........................Page S13

18. Table S4. QD size dependent electron injection and ET rates/efficiencies ..............Page S13

19. Figure S11. QD size dependent device energy diagram ....................................Page S13

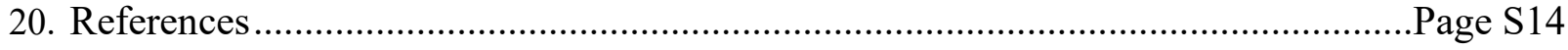




\section{Materials and Synthesis}

Dye/Bridge/Mediator Synthesis: 4,4'-(anthracene-9,10-diyl)bis(4,1-phenylene)diphosphonic acid (A), ${ }^{1}$ triphenyl-4,4'-diphosphonic acid (B) ${ }^{2}$ and $\mathrm{Co}^{\mathrm{II} / \mathrm{III}}$ tris $(1,10 \text {-phenanthroline })^{3}$ were synthesized according to previously published procedures.

$\mathrm{TiO}_{2}$ sol-gel preparation: $\mathrm{The}^{\mathrm{TiO}} 2$ nanoparticle paste was synthesized with slight modification to our previously published procedure. ${ }^{1,4}$ First, $7.3 \mathrm{~mL}(11 \mathrm{wt} \%)$ of tetraisopropyl orthotitanate was added dropwise $(110 \mathrm{~mL} / \mathrm{hr})$ to an ice cooled, rapidly stirring (300 rpm) $125 \mathrm{~mL}$ Erlenmeyer flask containing a solution of $0.42 \mathrm{~mL}$ nitric acid in $60 \mathrm{~mL}$ deionized water. The slurry was then stirred for $15 \mathrm{~min}$ after which the flask was covered with aluminum foil and heated up to $95{ }^{\circ} \mathrm{C}$. The sample was held at this temperature until the volume was reduced, through evaporation, to $18 \mathrm{~mL}$. The solution was placed in an acid digestion vessel (VWR, 25227-094) and heated in a box furnace (Thermo Scientific, BF51866A-1) at $230{ }^{\circ} \mathrm{C}$ for $10.5 \mathrm{~h}$. Upon cooling to room temperature, the solution was transferred to a glass vial. To the solution, $2 \mathrm{~g}(9.1 \mathrm{wt} \%)$ of carbowax copolymer (ground to powder with a mortar and pestle) was added and the mixture was stirred for $48 \mathrm{~h}$.

CdSe Quantum Dot Synthesis: According to a previous procedure, ${ }^{5} \mathrm{CdO}$ (300 mg), octadecene (20 $\mathrm{mL})$, and oleic acid ( $2 \mathrm{~mL}$ ) were added to $100 \mathrm{~mL}$ 3-neck round bottom flask and degassed while stirring under vacuum for three pump-fill cycles with $\mathrm{N}_{2}$. The reaction was heated up to $280{ }^{\circ} \mathrm{C}$ under $\mathrm{N}_{2}$ until the solution became colorless forming $\mathrm{Cd}(\text { oleate)})_{2}$. Then, the solution was cooled to $120{ }^{\circ} \mathrm{C}$ and Se powder $(100 \mathrm{mg})$ was added under an $\mathrm{N}_{2}$ stream. The reaction was then heated up to $240{ }^{\circ} \mathrm{C}$ and monitored using UV-Vis absorption spectroscopy. Aliquots were abstracted and measured every few minutes and once the desired absorption peak is reached, the reaction was quenched with toluene $(40 \mathrm{~mL})$ and immediately placed in an ice bath. The quantum dots were purified using centrifugation by first placing the reaction solution into $50 \mathrm{~mL}$ VWR centrifuge tubes and adding $10 \mathrm{~mL}$ acetone to every $15 \mathrm{~mL}$ of reaction solution to precipitate out excess precursors and left to sit for $5 \mathrm{~min}$. The suspension was then centrifuged, and the supernatant collected while the pellet is discarded. Methanol was then added in a 1:1 ratio between methanol and supernatant, then centrifuged forming an oil containing the QDs. The clear supernatant was then discarded, and the oil dispersed using toluene in a 1:1 ratio between toluene and oil. Methanol is then added in a 1:1 ratio between methanol and toluene that was added in the previous step and 
the mixture centrifuged forming another oil and the supernatant discarded. Next, the oil was dispersed with dichloromethane $(7 \mathrm{~mL})$ and flocculated with ethanol $(14 \mathrm{~mL})$ for three cycles collecting the solid pellet each time. Acetone $(14 \mathrm{~mL})$ was then added to the pellet and sonicated until the pellet was dispersed and centrifuged to further purify the product. Finally, the product was collected then dried under vacuum overnight and stored under $\mathrm{N}_{2}$ at $2{ }^{\circ} \mathrm{C}$.

\section{Photophysical and Electrochemical Measurements}

Absorption Spectra: Data were recorded on an Agilent $8453 \mathrm{UV}$-visible photo diode array spectrophotometer. Thin film absorption spectra were obtained by placing dry, derivatized $\mathrm{TiO}_{2}$ slides perpendicular to the detection of the beam path.

Incident Photon to Current Efficiency: Data were collected with a $\mathrm{CH}$ Instruments 630E electrochemical analyzer using a two-electrode configuration $\left(\mathrm{TiO}_{2}\right.$ working, $\mathrm{Pt}$ counter $)$ held at 0 $\mathrm{V}$ applied potential while monitoring the current. The samples were irradiated using the output from a housed Oriel Instruments $300 \mathrm{~W}$ Xe arc lamp (Newport, 6258) enclosed in an Oriel Research Arc-lamp Housing (Newport, 67005), single grating (1800 $\lambda \mathrm{mm}^{-1}, 250 \mathrm{~nm}$ blaze) Czerny-Turner monochromator every $5 \mathrm{~nm}$ at a $5 \mathrm{~nm}$ bandwidth. Excitation intensities of 0.8-1 $\mathrm{mW} \mathrm{cm} \mathrm{cm}^{-2}$ from 400-600 $\mathrm{nm}$ were measured at each wavelength using an Ophir Vega power meter (Ophir Vega 7Z01560) with a high-sensitivity power sensor (Ophir 3A-FS 7Z02628).

Amperometric $i-t$ : Data were collected using a $\mathrm{CH}$ Instruments $630 \mathrm{E}$ electrochemical analyzer using a two-electrode configuration $\left(\mathrm{TiO}_{2}\right.$ working, Pt counter) held at $0 \mathrm{~V}$ applied potential. The samples were irradiated with an AM1.5 solar spectrum generated from a $300 \mathrm{~W}$ Xe arc lamp (Newport, 6258) enclosed in an Oriel Research Arc-lamp Housing (Newport, 67005) with the light output passed through an AM1.5 Global filter (Newport, 81094). The light intensity was measured using a calibrated reference solar cell (Newport, 91150 V). A Model T132 Shutter Driver/Timer (UniBlitz) coupled to a mechanical shutter (Vincent Associates, VS25) was placed between the light source and sample to control light $(20 \mathrm{~s})$-dark $(5 \mathrm{~s})$ intervals over an $80 \mathrm{~s}$ time period. $J_{\text {sc }}$ Were reproducible across at least three independent samples with a standard deviation $\pm 3 \mu \mathrm{A} \mathrm{cm}^{-2}$. 
Current Density-Voltage Curves: Current density-voltage $(J-V)$ curves were measured by irradiating the devices with an AM1.5 Solar Spectrum generated from a $300 \mathrm{~W}$ Xe arc lamp (Newport, 6258) enclosed in an Oriel Research Arc-lamp Housing (Newport, 67005) with the light output passed through an AM1.5 Global filter (Newport, 81094) and then either a 375 or $455 \mathrm{~nm}$ LP filter. The light intensity was measured using a calibrated reference cell and meter (Newport, $91150 \mathrm{~V})$. Reported $J_{s c}, V_{o c}$, and $\eta$ values were the average of three independent cell measurements.

Intensity Dependence: Current density versus excitation power density plots were recorded using a $\mathrm{CH}$ Instruments 630E electrochemical analyzer with the working electrode attached to the anode $\left(\mathrm{TiO}_{2}\right.$ multi-layer film on FTO glass) and counter and reference electrodes attached to the cathode (Pt-coated FTO glass) in a sealed cell arrangement with $\mathrm{Co}^{\mathrm{II}} / \mathrm{Co}^{\mathrm{III}}$ (phen) $)_{3}$ mediator electrolyte. 532 $\mathrm{nm}$ (Aixiz, AD-532-400T) and $455 \mathrm{~nm}$ (Aixiz, AIX-445-A) lasers were used as the excitation source for 2.7/3.1 nm and $2.3 \mathrm{~nm}$ diameter QD devices, respectively. The outputs of both lasers were passed through a variable neutral density filter (Edinburgh F-B01 laser mount), a $1 \mathrm{~mm}$ diameter iris (Newport ID-1.0) and then directed to the sample via a flip mirror. An intensity meter (Ophir Vega 7Z01560) with a high sensitivity power sensor (Ophir Vega 3A-FS 7Z02628) was used to measure laser intensities. Threshold intensities were consistent across several devices.

Excitation events per second: The intensities, measured in $\mathrm{mW} \mathrm{cm} \mathrm{cm}^{-2}$, were converted to excitations $\mathrm{s}^{-1} \mathrm{~cm}^{-2}$ using the equation $I_{e x}=\frac{I_{m W}}{1000} \times \frac{\% A(\lambda)}{E_{J}(\lambda)}$, where $I_{e x}$ is the intensity given in excitations s $\mathrm{cm}^{-}$ ${ }^{2}, I_{m W}$ is the intensity in $\mathrm{mW} \mathrm{cm} \mathrm{cm}^{-2}, \% A(\lambda)$ is the absorptance of the film at the excitation wavelength, $\lambda$, and $E_{J}(\lambda)$ is the energy, in joules, of a photon of wavelength $\lambda$.

Steady-State Emission: Emission spectra were recorded at room temperature using an Edinburgh FLS980 fluorescence spectrometer. The samples were excited using the same $532 \mathrm{~nm}$ laser passed through neutral density filter (same as described above), a $1 \mathrm{~mm}$ diameter iris (Newport ID-1.0), and then directed to the sample via a flip mirror. Emission was detected by a Peltier-cooled Hamamatsu R928 photomultiplier tube (emission slit widths held at $3.0 \mathrm{~nm}, 1 \mathrm{~nm}$ step, with a 532 $\mathrm{nm}$ notch filter). An intensity meter (Ophir Vega 7Z01560) with a high sensitivity power sensor 
(Ophir Vega 3A-FS 7Z02628) was used to measure laser intensities. Samples were prepared in a glovebox under a $\mathrm{N}_{2}$ atmosphere.

Time-Resolved Emission: Time-resolved emission traces were acquired using the same spectrometer as the steady-state emission measurements. The emission decay traces were acquired using time-correlated single-photon counting (TCSPC; 1024 channels; 200 ns window) with data collection for 5000 counts. TCSPC excitation was provided by an Edinburgh EPL-445 ps pulsed light emitting diode (445 $\pm 8 \mathrm{~nm}$, pulse width $100 \mathrm{ps}$ ) operated at $10 \mathrm{MHz}$.

Lifetime determination: Emission decay kinetics for the films were fit with a biexponential function $y=A_{1} e^{-x / \tau_{1}}+A_{2} e^{-x / \tau_{2}}+y_{0}$ using the Edinburgh software package and a weighted average lifetime was calculated using $\langle\tau\rangle=\sum A_{i} \tau_{i}^{2} / \sum A_{i} \tau$.

Transient Absorption: Transient absorption (TA) measurements were carried out by inserting sealed samples $(2.2 \times 2.2 \mathrm{~cm}$ with a $1 \times 1 \mathrm{~cm}$ active area $)$ perpendicular to the light source in a collinear arrangement. The spectrometer is composed of a Continuum Surelite EX Nd:YAG laser combined with a Continuum Horizon OPO $(532 \mathrm{~nm}, 5-7 \mathrm{~ns}$, operated at $1 \mathrm{~Hz}$, beam diameter $\sim 0.5$ $\mathrm{cm}, 2.5-5 \mathrm{~mJ} /$ pulse) integrated into a commercially available Edinburgh LP980 laser flash photolysis spectrometer system. White light probe pulses generated by a pulsed $150 \mathrm{~W}$ Xe lamp were passed through the sample, focused into the spectrometer, and then detected by intensified Andor iStar CCD camera. Time-resolved scans were passed through a TMS302-A monochromator (1800 grooves/mm grating) with a $300 \mathrm{~mm}$ focal length in Czerny Turner configuration and detected by a Hamamatsu R928 side window PMT. Detector outputs were processed using Edinburgh's L900 (version 8.2.3, build 0) software package. 


\section{Energy Level Calculations for Figure 1 and S11}

The ground state reduction potential and excited state oxidation potentials of QD were acquired from literature. ${ }^{6}$ Redox potentials for $\mathrm{TiO}_{2}, \mathbf{A}$, and $\mathrm{Co}^{\mathrm{II} / \mathrm{III}}$ (phen) $)_{3}$ were obtained from our previous publication. ${ }^{1}$

Table S1. Photophysical properties of QDs in in $\mathrm{N}_{2}$ deaerated DCM.

$\begin{array}{cccccccc}\mathrm{D}_{\mathbf{Q D}}(\mathrm{nm}) & \begin{array}{c}\lambda_{\mathrm{abs}}(\mathrm{nm}) \\ \left(\varepsilon, \mathrm{x} 10^{4} \mathrm{M}^{-1} \mathrm{~cm}^{-1}\right)\end{array} & \begin{array}{c}\mathrm{E}_{\mathrm{CB}} \\ (\mathrm{V})^{\mathrm{d}}\end{array} & \tau_{1}(\mathrm{~ns}) & \mathrm{A}_{1} & \tau_{2}(\mathrm{~ns}) & \mathrm{A}_{2} & \langle\tau\rangle(\mathrm{ns}) \\ 2.3^{\mathrm{a}} & 490(5.1) & -1.51 & 5.2 & 2798 & 42.0 & 439 & 26 \\ 2.7^{\mathrm{b}} & 527(7.8) & -1.43 & 9.2 & 2169 & 46.5 & 428 & 28 \\ 3.1^{\mathrm{c}} & 550(11.6) & -1.36 & 15.5 & 218 & 43.2 & 113 & 32\end{array}$

(a) $\lambda_{\mathrm{ex}}=360 \mathrm{~nm}, \lambda_{\mathrm{em}}=510 \mathrm{~nm}$, (b) $\lambda_{\mathrm{ex}}=360 \mathrm{~nm}, \lambda_{\mathrm{em}}=545 \mathrm{~nm}$, (c) $\lambda_{\mathrm{ex}}=360 \mathrm{~nm}, \lambda_{\mathrm{em}}=580 \mathrm{~nm}$ (d) calculated from reference 6 .

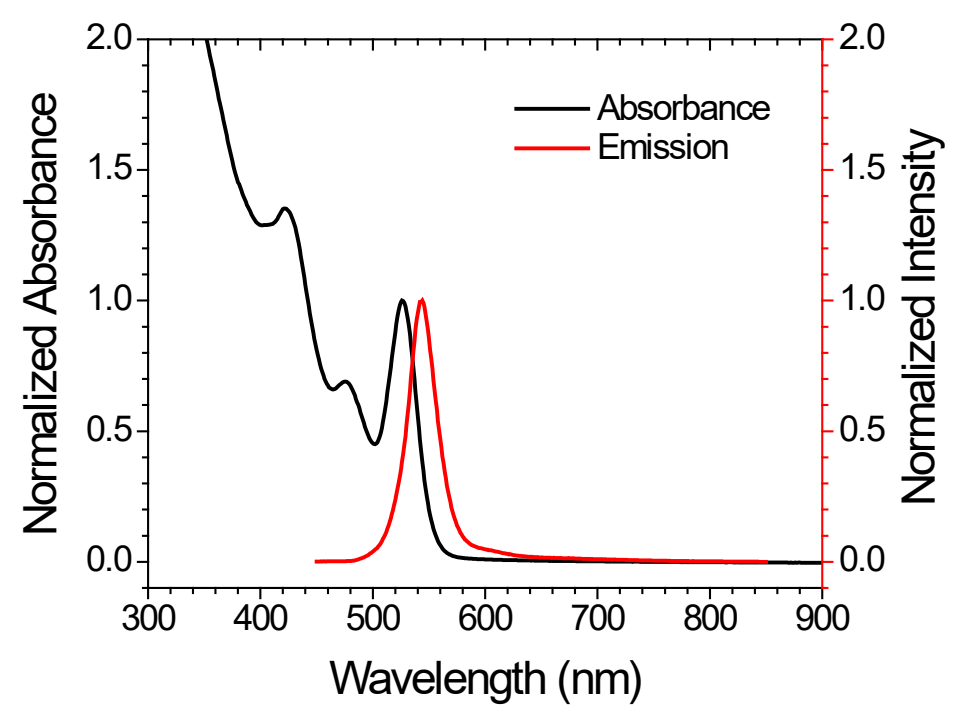

Figure S1. Normalized absorbance and emission $\left(\lambda_{\mathrm{ex}}=360 \mathrm{~nm}\right)$ spectra for QD $(2.7 \mathrm{~nm})$ in $\mathrm{N}_{2}$ deaerated toluene. 
Equation S1-2. QD diameter $(D)$ and extinction coefficients $(\epsilon)$ were calculated using equations S1 and S2, respectively, according to a previously published procedure. ${ }^{6}$

$$
\begin{gathered}
D=\left(1.6122 \times 10^{-9}\right) \lambda^{4}-\left(2.6575 \times 10^{-6}\right) \lambda^{3}+\left(1.6242 \times 10^{-3}\right) \lambda^{2}-(0.4277) \lambda+41.57 \\
(\mathrm{~S} 1) \\
\epsilon=5857(D)^{2.65} \quad(\mathrm{~S} 2)
\end{gathered}
$$

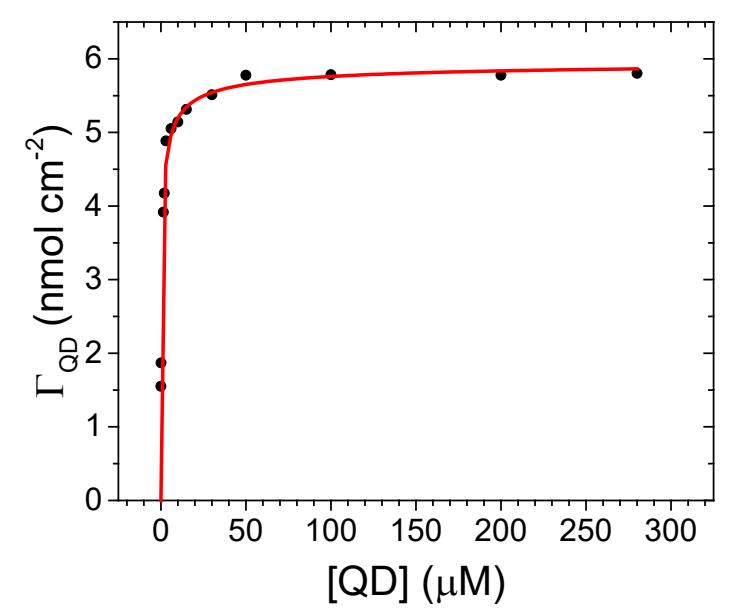

Figure S2. QD surface coverage $\left(\Gamma_{\mathrm{QD}}\right)$ versus $[\mathbf{Q D}]$ for $\mathrm{TiO}_{2}-\mathbf{B}$ films immersed into $\mathbf{Q D}$ in DCM for $24 \mathrm{~h}$ from $0.09-280 \mu \mathrm{M}$ (all points are an average of two films). 


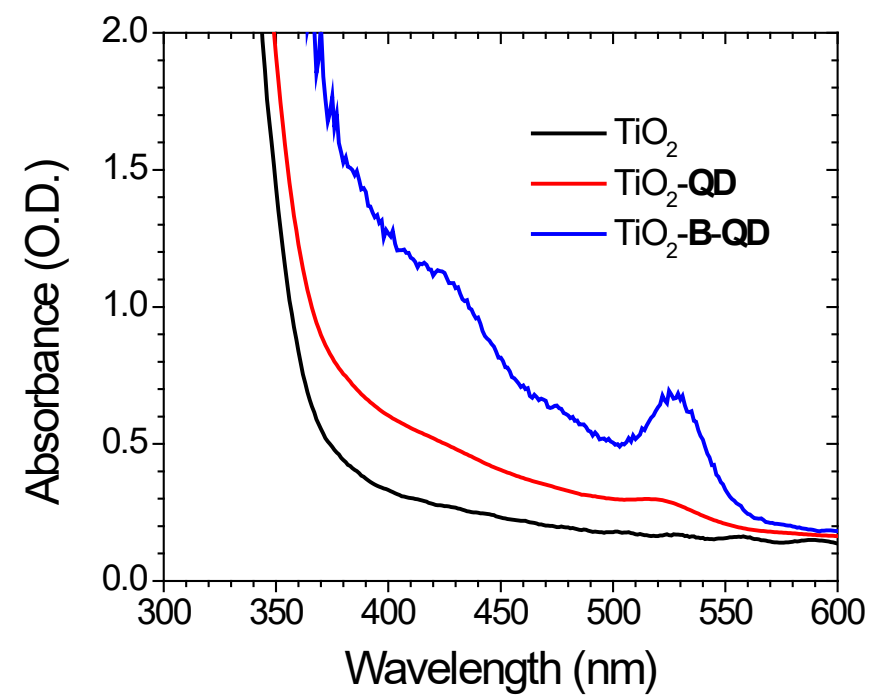

Figure S3. Absorption spectrum of $\mathrm{TiO}_{2}$ films with and without $\mathbf{B}$ after soaking in $50 \mu \mathrm{M}$ QD.

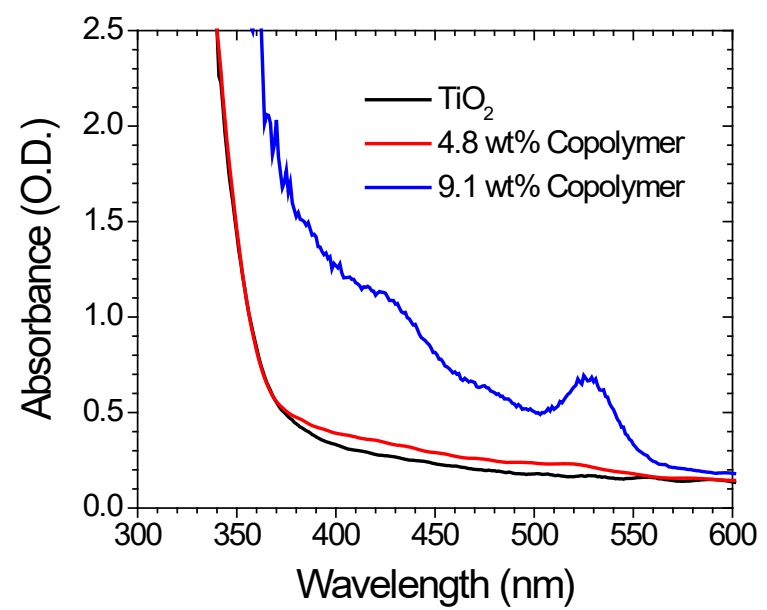

Figure S4. Absorption spectrum of $\mathrm{TiO}_{2}-\mathbf{B}-\mathbf{Q D}$ films prepared from $\mathrm{TiO}_{2}$ sintered at $500{ }^{\circ} \mathrm{C}$ with $4.8 \mathrm{wt} \%$ copolymer (red) and with $9.1 \mathrm{wt} \%$ copolymer (blue). 
a)

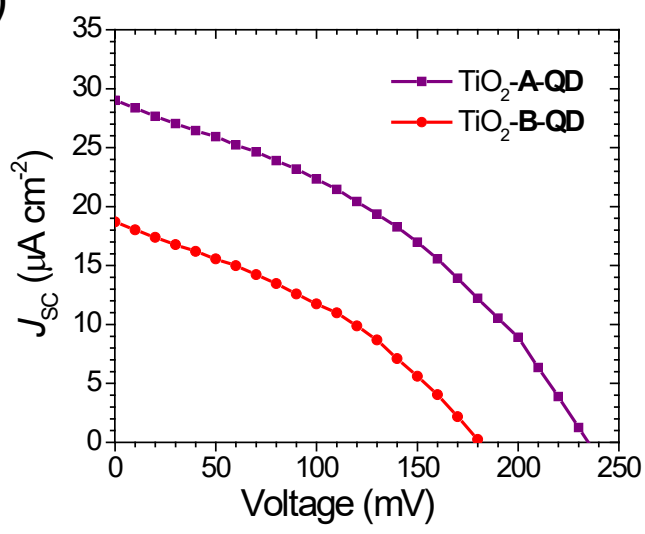

b)

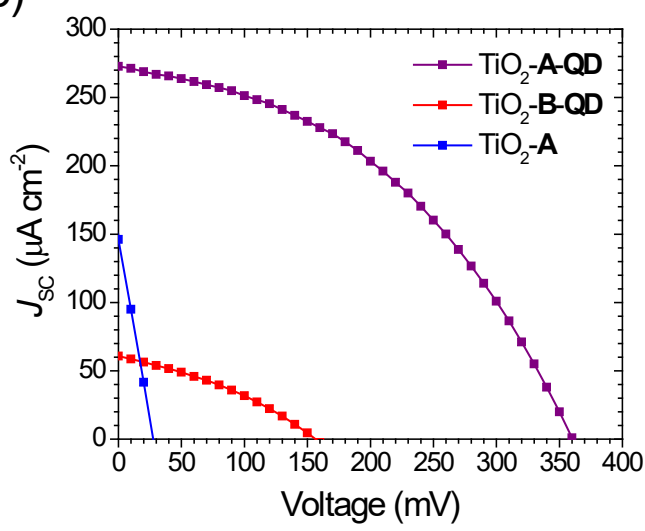

Figure S5. Current density-voltage measurements for monolayer and bilayer films under AM1.5 solar intensities for $2.7 \mathrm{~nm}$ QD films using (a) $455 \mathrm{~nm}$ and (b) $375 \mathrm{~nm}$ LP filter (curves are an average of three independent devices).

Table S2. Device performance metrics under 1 sun AM1.5 irradiation for $2.7 \mathrm{~nm}$ QD films.

$\begin{array}{ccccc}\text { Device } & \text { Filter }(\mathrm{nm}) & J_{\text {sc }}\left(\mu \mathrm{A} \mathrm{cm}^{-2}\right) & V_{\text {oc }}(\mathrm{mV}) & \eta(\%) \\ \mathrm{TiO}_{2} \text {-B-QD } & 455 & 19 & 180 & 0.0012 \\ \mathrm{TiO}_{2} \text {-A-QD } & 455 & 29 & 230 & 0.0024 \\ \mathrm{TiO}_{2} \text {-A } & 375 & 150 & 30 & 0.0011 \\ \mathrm{TiO}_{2} \text {-B-QD } & 375 & 60 & 160 & 0.0032 \\ \mathrm{TiO}_{2} \text {-A-QD } & 375 & 272 & 360 & 0.0430\end{array}$



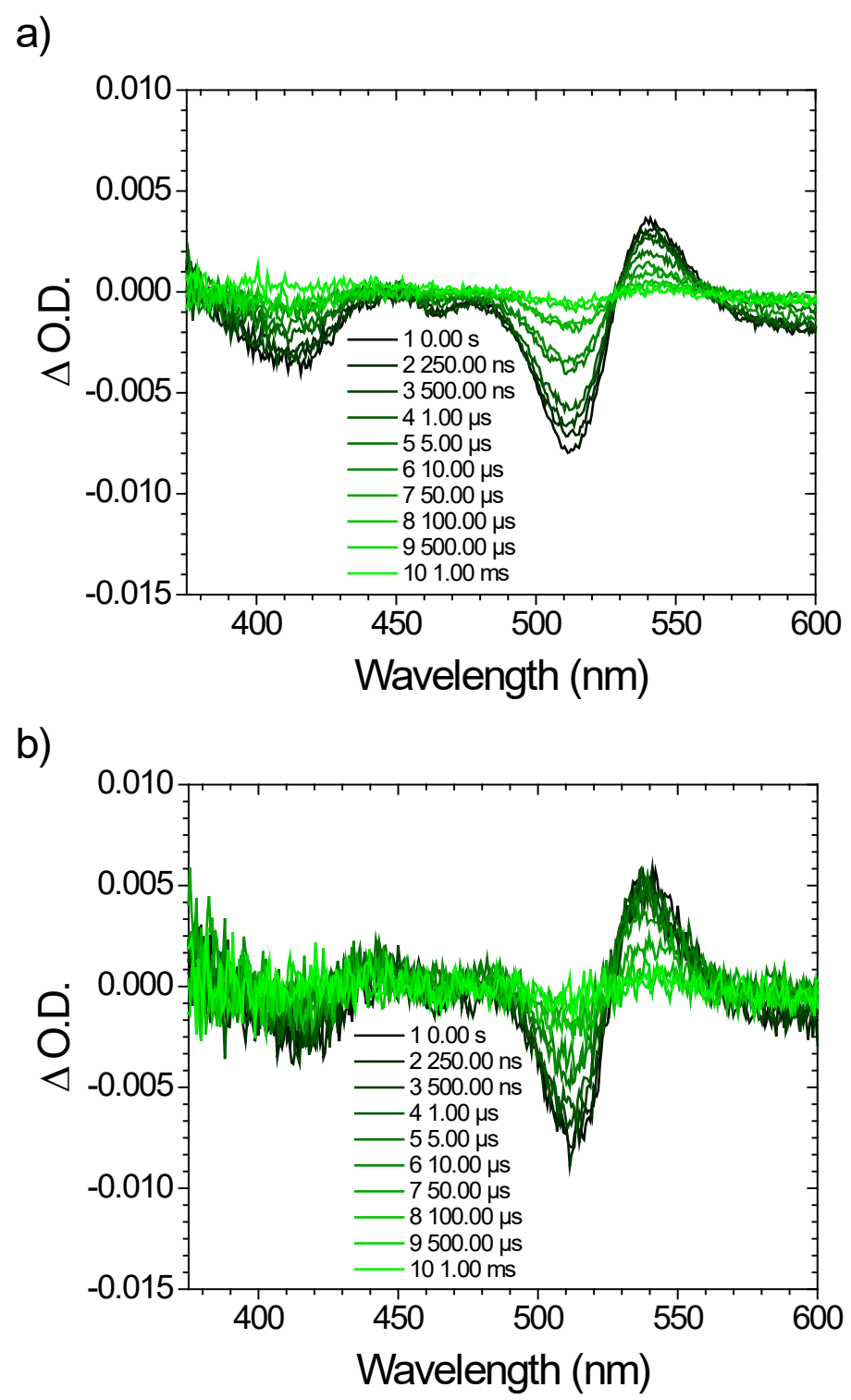

Figure S6. Transient absorption spectra for $\mathrm{TiO}_{2}-\mathbf{B}-\mathbf{Q D}$ films (a) without and (b) with $\mathrm{Co}^{\mathrm{II} / \mathrm{III}}(\text { phen })_{3}$ in $\mathrm{MeCN}$. 
a)

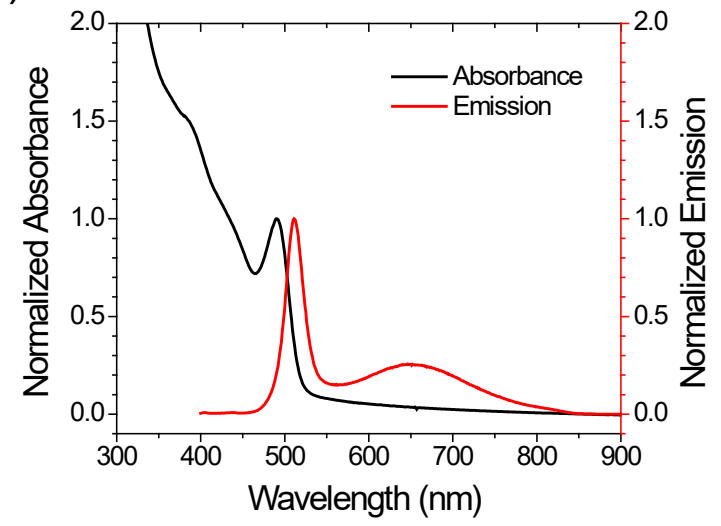

b)

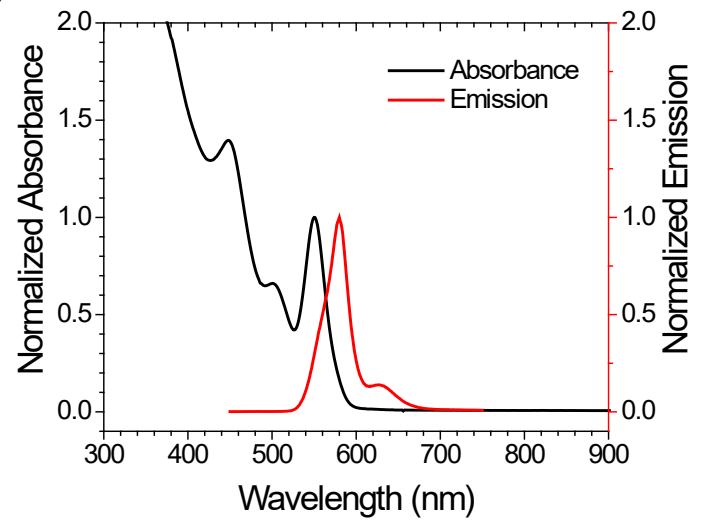

Figure S7. Normalized absorbance and emission $\left(\lambda_{\mathrm{ex}}=360 \mathrm{~nm}\right)$ spectra for $2.3 \mathrm{~nm}$ (a) and 3.1 $\mathrm{nm}$ (b) diameter QDs in $\mathrm{N}_{2}$ deaerated toluene.

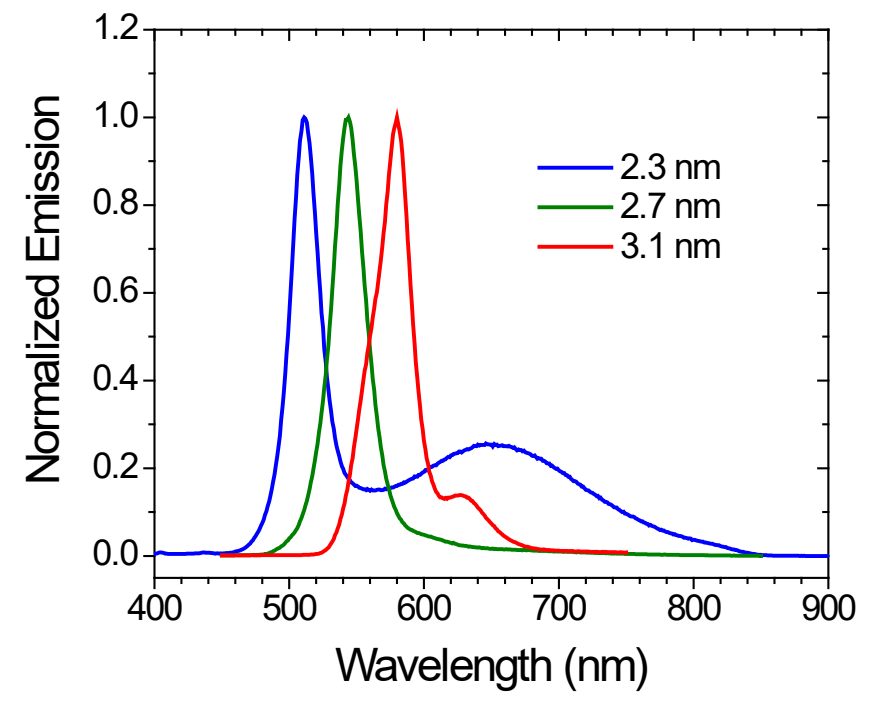

Figure S8. Normalized emission spectra for QD of different diameters in toluene $\left(\lambda_{\mathrm{ex}}=360 \mathrm{~nm}\right.$, $395 \mathrm{~nm}$ LP filter). 
a)

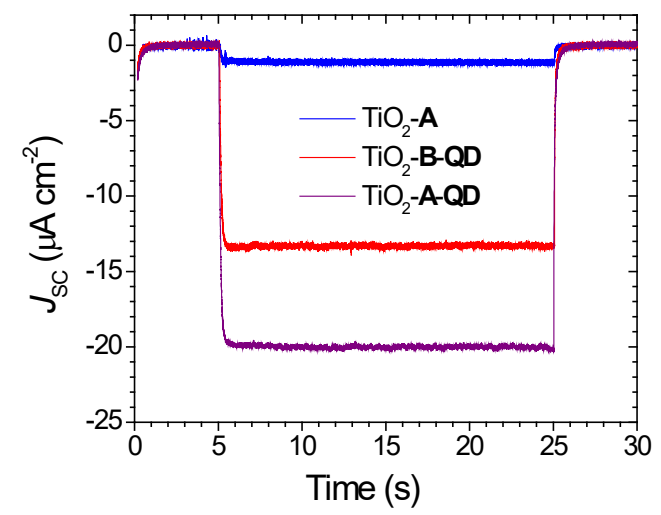

b)

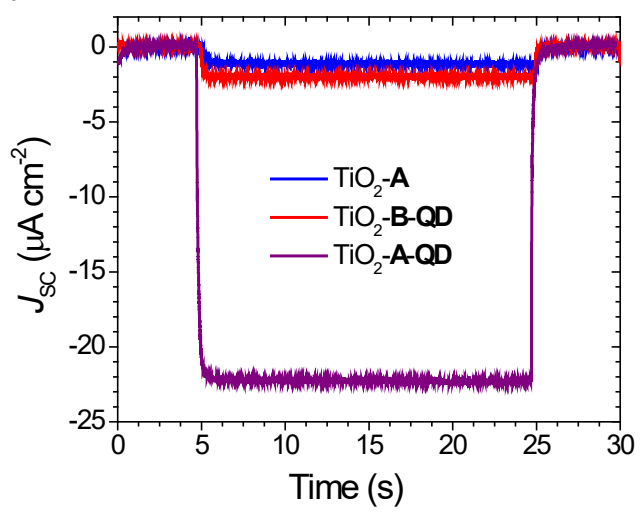

Figure S9. Amperometric $i-t$ measurements for films using (a) $2.3 \mathrm{~nm}$ and (b) $3.1 \mathrm{~nm}$ diameter QD under AM1.5 solar irradiance passed through a $455 \mathrm{~nm} \mathrm{LP} \mathrm{filter}(\mathrm{V}=0 \mathrm{~V}$; shutter open at $\mathrm{t}$ $=0 \mathrm{~s}$, shutter closed at $\mathrm{t}=20 \mathrm{~s}$ ).

a)

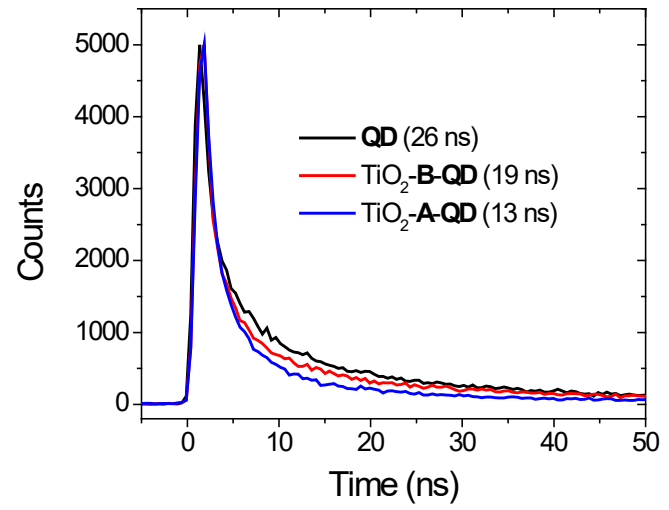

b)

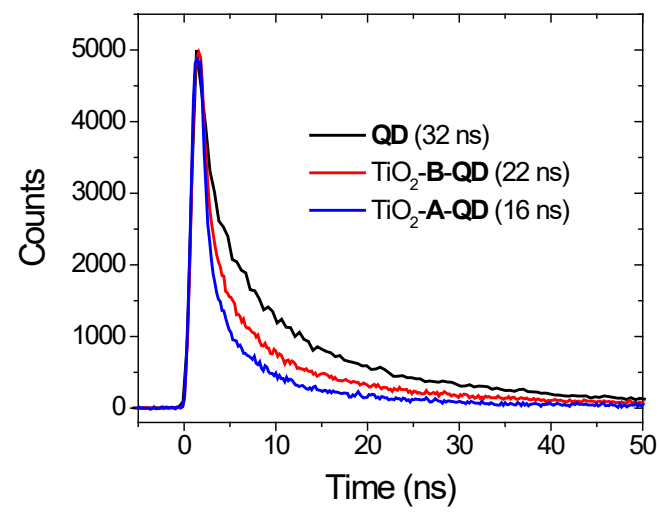

Figure S10. Time-resolved emission measurements for $\mathrm{TiO}_{2}-\mathbf{B}-\mathbf{Q D}$ and $\mathrm{TiO}_{2}-\mathbf{A}-\mathbf{Q D}$ films using (a) $2.3 \mathrm{~nm}\left(\lambda_{\mathrm{ex}}=445 \mathrm{~nm}, \lambda_{\mathrm{em}}=510 \mathrm{~nm}\right)$ and (b) $3.1 \mathrm{~nm}$ QD diameters $\left(\lambda_{\mathrm{ex}}=445 \mathrm{~nm}, \lambda_{\mathrm{em}}=580\right.$ $\mathrm{nm})$. 
Table S3. Kinetic fitting parameters for the time-resolved emission traces for $\mathrm{TiO}_{2}-\mathbf{X}-\mathbf{Q D}$ films in $\mathrm{N}_{2}$ deaerated $\mathrm{MeCN}$ where $\mathrm{X}=\mathbf{A}$ or $\mathbf{B}$.

$\begin{array}{cccccc}\text { Sample } & \tau_{1}(\mathrm{~ns}) & \mathrm{A}_{1} & \tau_{2}(\mathrm{~ns}) & \mathrm{A}_{2} & \langle\tau\rangle(\mathrm{ns}) \\ \text { B-QD }(2.3 \mathrm{~nm})^{\mathbf{a}} & 3.4 & 2273 & 28.1 & 510 & 19 \\ \text { A-QD }(2.3 \mathrm{~nm})^{\mathbf{a}} & 2.9 & 2831 & 21.7 & 425 & 13 \\ \text { B-QD }(2.7 \mathrm{~nm})^{\mathbf{b}} & 4.3 & 2891 & 31.6 & 406 & 18 \\ \text { B-QD }(2.7 \mathrm{~nm})^{\mathbf{b}, \mathbf{d}} & 1.5 & 1127 & 10.7 & 280 & 7 \\ \text { A-QD }(2.7 \mathrm{~nm})^{\mathbf{b}} & 2.3 & 2361 & 18.5 & 243 & 10 \\ \text { B-QD }(3.1 \mathrm{~nm})^{\mathbf{c}} & 7.1 & 1541 & 37.5 & 286 & 22 \\ \text { A-QD }(3.1 \mathrm{~nm})^{\mathbf{c}} & 5.3 & 673 & 23.5 & 211 & 16\end{array}$

(a) $\lambda_{\mathrm{ex}}=445 \mathrm{~nm}, \lambda_{\mathrm{em}}=510 \mathrm{~nm}$, (b) $\lambda_{\mathrm{ex}}=445 \mathrm{~nm}, \lambda_{\mathrm{em}}=545 \mathrm{~nm}$, (c) $\lambda_{\mathrm{ex}}=445 \mathrm{~nm}, \lambda_{\mathrm{em}}=580 \mathrm{~nm}$, (d) with $0.2 / 0.02 \mathrm{M} \mathrm{Co}^{\mathrm{II} / \mathrm{III}}(\text { phen })_{3}$ redox mediator.

Table S4. Energy transfer rates and efficiencies for $\mathrm{TiO}_{2}-\mathbf{X}-\mathbf{Q D}$ films in $\mathrm{N}_{2}$ deaerated $\mathrm{MeCN}$ where $\mathrm{X}=\mathbf{A}$ or $\mathbf{B}$.

$\begin{array}{ccccc}\text { Sample } & k_{\text {inj }}\left(\times 10^{7} \mathrm{~s}^{-1}\right) & \Phi_{\text {inj }}(\%) & k_{\mathrm{ET}}\left(\times 10^{7} \mathrm{~s}^{-1}\right) & \Phi_{\mathrm{ET}}(\%) \\ \text { QD }(2.3 \mathrm{~nm}) & 1.4 & 27 & 2.4 & 32 \\ \text { QD }(2.7 \mathrm{~nm}) & 2.0 & 36 & 4.4 & 44 \\ \text { QD }(3.1 \mathrm{~nm}) & 1.4 & 31 & 1.7 & 27\end{array}$

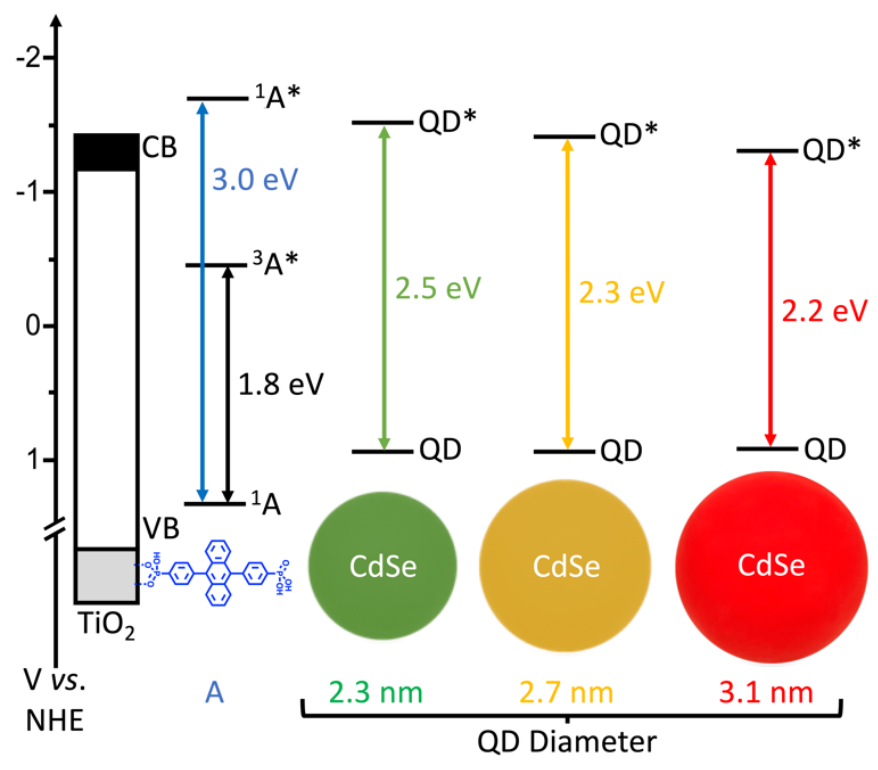

Figure S11. Energetics of $\mathrm{TiO}_{2}$, A and the QDs of various diameters. 


\section{References}

1. Hill, S. P.; Banerjee, T.; Dilbeck, T.; Hanson, K., Photon Upconversion and Photocurrent Generation via Self-Assembly at Organic-Inorganic Interfaces. The Journal of Physical Chemistry Letters 2015, 6 (22), 4510-4517.

2. Wang, J. C.; Murphy, I. A.; Hanson, K., Modulating Electron Transfer Dynamics at DyeSemiconductor Interfaces via Self-Assembled Bilayers. The Journal of Physical Chemistry C 2015, 119 (7), 3502-3508.

3. Feldt, S. M.; Gibson, E. A.; Gabrielsson, E.; Sun, L.; Boschloo, G.; Hagfeldt, A., Design of Organic Dyes and Cobalt Polypyridine Redox Mediators for High-Efficiency Dye-Sensitized Solar Cells. Journal of the American Chemical Society 2010, 132 (46), 16714-16724.

4. Lee, S.-H. A.; Abrams, N. M.; Hoertz, P. G.; Barber, G. D.; Halaoui, L. I.; Mallouk, T. E., Coupling of Titania Inverse Opals to Nanocrystalline Titania Layers in Dye-Sensitized Solar Cells. The Journal of Physical Chemistry B 2008, 112 (46), 14415-14421.

5. Knauf, R. R.; Lennox, J. C.; Dempsey, J. L., Quantifying Ligand Exchange Reactions at CdSe Nanocrystal Surfaces. Chemistry of Materials 2016, 28 (13), 4762-4770.

6. Yu, W. W.; Qu, L.; Guo, W.; Peng, X., Experimental Determination of the Extinction Coefficient of CdTe, CdSe, and CdS Nanocrystals. Chemistry of Materials 2003, 15 (14), 2854-2860. 